\title{
Single-Crystalline Ferroelectric Thin Films by Ion Implantation and Direct Wafer Bonding
}

\author{
I. SZAFRANIAK, I. RADU, R. SCHOLZ, M. ALEXE, \\ and U. GÖSELE \\ Max Planck Institute of Microstructure Physics, Weinberg 2, \\ 06120 Halle, Germany
}

(Received April 25, 2003)

Layer splitting by helium and/or hydrogen implantation and wafer bonding was applied to transfer thin single-crystalline ferroelectric layers onto different substrates. The optimum conditions for achieving blistering/splitting after post-implantation annealing were experimentally obtained for $\mathrm{LiNbO}_{3}, \mathrm{LaAlO}_{3}, \mathrm{SrTiO}_{3}$ single crystals and PLZT ceramic. Under certain implantation conditions large area exfoliation instead of blistering occurs after annealing of as-implanted substrates. Small area single-crystalline layer transfer was successfully achieved.

Keywords: Layer transfer; ferroelectric thin film; ion implantation

\section{INTRODUCTION}

Ferroelectric perovskites have a large number of applications spanning from ferroelectric memories to micromechanical devices. Some applications, especially in optical or electro-optical devices, require an extremely good quality of thin layers. Oxide thin films can be obtained by different deposition methods including pulsed laser deposition, chemical vapor deposition or sol-gel, but they usually contain imperfections like grain boundaries, a high density of dislocations etc. Such layers have different properties than bulk single crystals, e.g., the electro-optic response of films is much smaller and the light propagation losses are high, and this hampers application for optical devices. Recently, the approach of layer transfers by ion implantation and wafer bonding, well-known from silicon technology [1], has been applied in order to achieving high quality single crystalline ferroelectric layers with the prospect of their integration into silicon technology. This method, also known as "smart-cut ${ }^{\circledR}$," "layer splitting" or "layer exfoliation," was first introduced by Bruel [2] in 1995 as a highly effective method for the 
fabrication of high quality silicon-on-insulator (SOI) wafers. Briefly, a donor wafer is implanted with helium and/or hydrogen at appropriate energy with doses ranging from $10^{16}$ up to $10^{17} \mathrm{~cm}^{-2}$ [3]. The as-implanted donor wafer is then bonded to a host wafer and annealed at elevated temperatures, first to increase the bonding energy, and then to achieve splitting. It was previously shown that in order to achieve splitting after a post implantation annealing the wafer temperature during implantation must fall within a window that is specific to each material [4]. Application of the layer splitting approach to complex oxides is very attractive by offering an alternative method to fabricate thin single-crystalline oxide films with thickness in the sub-micron and micron range on any substrate at low temperatures [5].

Unfortunately, the temperature window of perovskite oxides is rather narrow making the layer transfer a relatively difficult process $[4,6]$. The present paper shows our latest achievements concerning layer splitting of oxide materials including the optimization of the implantation parameters as well as the annealing conditions for layer splitting. It also shows the transfer of small area single crystalline oxide layers with sub-micron thickness.

\section{EXPERIMENTAL}

In the present study $10 \times 10 \times 1 \mathrm{~mm}^{3}$ substrates of single-crystalline $\mathrm{SrTiO}_{3}$ (STO), $\mathrm{LiNbO}_{3}(\mathrm{LNO}), \mathrm{LaAlO}_{3}(\mathrm{LAO})$ and polycrystalline PLZT were used. Hydrogen $\left(\mathrm{H}_{2}^{+}\right)$and/or helium $\left(\mathrm{He}^{+}\right)$implantation was performed in a standard implanter. To minimize ion channeling implantation was performed under $7^{\circ}$ sample tilt. $\mathrm{H}_{2}^{+}$was implanted at $130-160 \mathrm{keV}$ with different doses from $2 \times 10^{16}$ to $5 \times 10^{16} \mathrm{~cm}^{-2}$, while $\mathrm{He}^{+}$was implanted at $105 \mathrm{keV}$ with $5 \times 10^{16} \mathrm{~cm}^{-2}$ for single ion implantation experiments. The influence of a two-step $\mathrm{He}+\mathrm{H}$ co-implantation on blistering/splitting of oxide materials was also investigated: a low $\mathrm{He}^{+}$dose $\left(5.0 \times 10^{15} \mathrm{~cm}^{-2}\right)$ was first implanted at $105 \mathrm{keV}$ followed by range matched $\mathrm{H}_{2}^{+}\left(2.0-5.0 \times 10^{16} \mathrm{~cm}^{-2}\right)$ implantation. Ion implantation was performed at different temperatures ranging from room-temperature (RT) up to $300^{\circ} \mathrm{C}$.

The as-implanted samples were annealed in air at a temperature ranging from $250^{\circ} \mathrm{C}$ up to $700^{\circ} \mathrm{C}$. Nomarski optical microscopy, atomic force microscopy (AFM) and scanning electron microscopy (SEM) were used to investigate blister formation and exfoliation. Formation of platelet-like defects and their evolution after annealing were analyzed by cross section transmission electron microscopy (XTEM) at $200 \mathrm{kV}$. SEM and TEM were used also for investigation of transferred layers. 


\section{RESULTS AND DISCUSSIONS}

\section{Blistering and Exfoliation}

During implantation a high density of extended defects such as platelets, bubbles and micro-cracks are created. These defects are nucleation centers for the agglomeration of diffusing $\mathrm{He}$ or $\mathrm{H}$ during annealing. Both, blistering and layer splitting are connected with the evolution of micro-cracks filled with $\mathrm{He}$ and/or $\mathrm{H}$. For as-implanted samples that are not bonded to another substrate surface blistering usually occurs during annealing. Layer splitting is observed if the implanted surface is stiffened by bonding the implanted wafer to a handling wafer.

In order to find the optimum implantation conditions all samples were investigated directly after implantation and after annealing. It was observed that if the implanted temperature was above an optimum value blistering/exfoliation occurs directly during implantation. If the temperature during implantation is too low no blistering/exfoliation was obtained even after high temperature annealing (up to $700^{\circ} \mathrm{C}$ ). The optimum implantation conditions (presented in Table I) were determined by the lack of blisters in as-implanted substrates and their appearance after thermal treatment. As it can be seen in Table I STO and LNO require RT- implantation, while for PLZT and LAO higher implantation temperatures are needed $\left(200^{\circ} \mathrm{C}\right.$ and $200-300^{\circ} \mathrm{C}$, respectively).

During the blistering experiments it was unexpectedly observed that certain implantation conditions lead to large area exfoliation instead of blistering after annealing of as-implanted samples. This was the case for $\mathrm{H}$-implanted STO, He-implanted LNO as well as for $\mathrm{He}+\mathrm{H}$ co-implanted STO (Fig. 1), while after annealing of $\mathrm{H}$-implanted LAO and He-implanted PLZT broken blisters were observed (Fig. 2).

TABLE I Optimum implantation parameters for achieving blistering or splitting after a thermal treatment

\begin{tabular}{lccc}
\hline Material & Dose $\left(\mathrm{cm}^{-2}\right)$ & Energy $(\mathrm{keV})$ & Temperature $\left({ }^{\circ} \mathrm{C}\right)$ \\
\hline $\mathrm{LaAlO}_{3}$ & $5 \times 10^{16} \mathrm{H}_{2}^{+}$ & 130 & $200-300$ \\
$\mathrm{PLZT}$ & $5 \times 10^{16} \mathrm{He}^{+}$ & 105 & 200 \\
$\mathrm{LiNbO}_{3}$ & $5 \times 10^{16} \mathrm{He}^{+}$ & 105 & $\mathrm{RT}$ \\
$\mathrm{SrTiO}_{3}$ & $5 \times 10^{16} \mathrm{H}_{2}^{+}$ & $130-160$ & $\mathrm{RT}$ \\
$\mathrm{SrTiO}_{3}$ & $5 \times 10^{15} \mathrm{He}^{+}$ & 105 & $\mathrm{RT}$ \\
& $+2-5 \times 10^{16} \mathrm{H}_{2}^{+}$ & 160 & \\
\hline
\end{tabular}




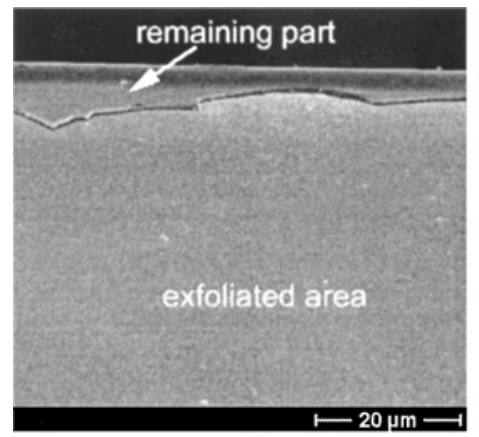

a)

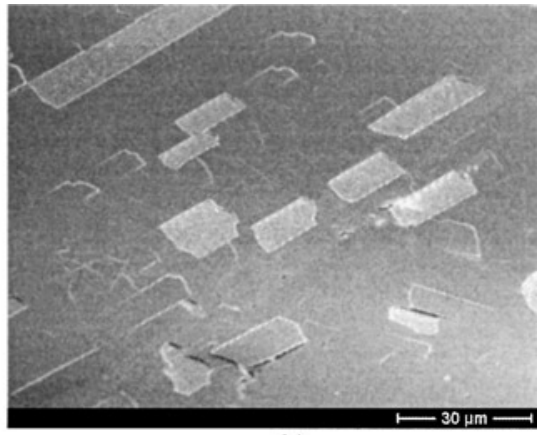

b)

FIGURE 1 Large area exfoliation obtained after $500^{\circ} \mathrm{C}$ annealing of a) $\mathrm{H}$-implanted STO and b) He-implanted LNO.

Cross section TEM investigation (Fig. 3(a)) has shown that a high density of H-platelets of about $10 \mathrm{~nm}$ lateral size is formed during $\mathrm{H}$-implantation into STO. The platelets are mostly distributed at the end region of the implanted layer and are mostly oriented parallel to the implanted surface. As can be seen from Fig. 3(b), H-platelets in as-implanted LAO have larger lateral sizes. They are mostly oriented on (100) planes but some of them have (111)-orientation and they are distributed over the whole damaged region. A similar distribution of He-platelets is observed in PLZT (Fig. 3(c)). It was surprising that although PLZT is a polycrystalline ceramic material the platelets in different grains have orientations parallel to the implantation surface. On the basis of TEM analysis it can be supposed that large area

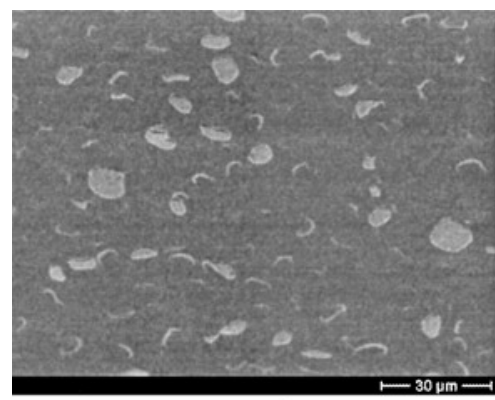

a)

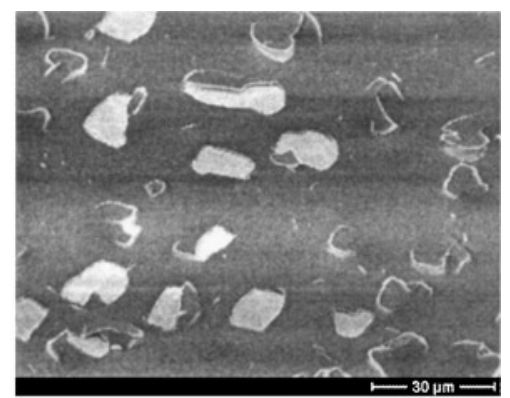

b)

FIGURE 2 SEM images of a) He-implanted PLZT and b) after high temperature treatment at $500^{\circ} \mathrm{C}$. 


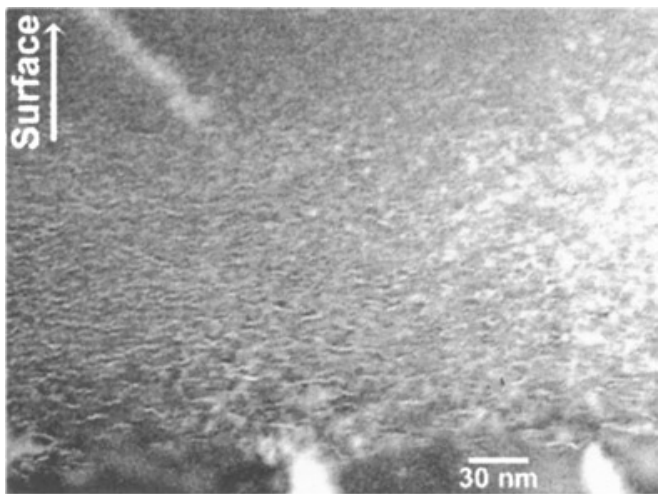

a)

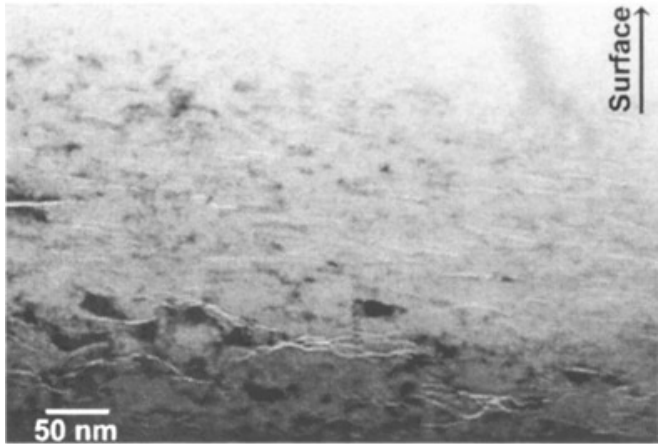

b)

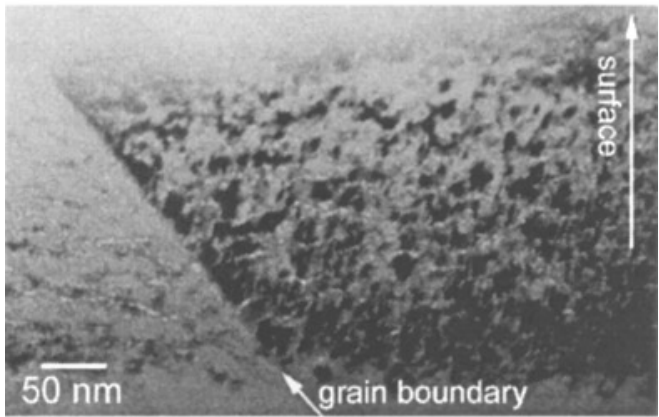

c)

FIGURE 3 Cross-section TEM images showing platelets in as-implanted a) STO (implanted with $5.0 \times 10^{16} \mathrm{H}_{2}^{+} / \mathrm{cm}^{2}$ at RT) b) LAO (implanted with $5.0 \times 10^{16}$ $\mathrm{H}_{2}^{+} / \mathrm{cm}^{2}$ at $300^{\circ} \mathrm{C}$ ) and c) PLZT (implanted with $5.0 \times 10^{16} \mathrm{He}^{+} / \mathrm{cm}^{2}$ at $200^{\circ} \mathrm{C}$ ). 
exfoliation is connected with a small size and/or a narrow distribution of platelets at the end of the damage region and their evolution during annealing.

\section{Layer Splitting}

Single crystalline substrates, implanted at optimum conditions (see Table I), were used for layer splitting. The first attempt to direct bonding failed due to a relatively high micro-roughness (e.g., the RMS roughness of the implanted STO and host STO substrate surfaces was about $1 \mathrm{~nm}$ ). Therefore, different bonding procedures via various intermediate layers such as spin-on glass (SOG), Au, polymeric layer etc., were used to transfer oxide layers onto different substrates. Successful layer transfers of single-crystalline STO and LAO have been achieved by annealing of the bonded pairs at $300^{\circ} \mathrm{C}$ (see Fig. 4). Nevertheless, due to non-homogeneity of the bonding interface and thermal mismatch, the transferred layers shattered into pieces of several hundred microns across. TEM investigations showed that the transferred STO layer is about $500 \mathrm{~nm}$ thick (Fig. 5), which agrees with the value calculated from TRIM (transport-of-ion-in-mater) simulation [7]. The surface after splitting has a relatively high micro-roughness due to crack formation within the sacrificial layer during post-implantation thermal treatment. The good crystal structures of the transferred layers remain after ion implantation, bonding and splitting, which was confirmed by diffraction pattern (Fig. 5, inset).

To avoid effects caused by the non-homogeneity of intermediate layers and bonded interface direct wafer bonding should be used. However, it is

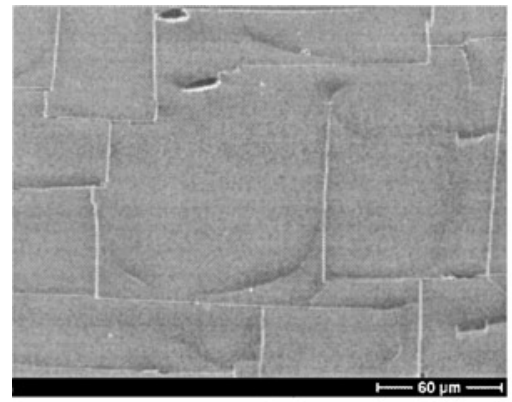

a)

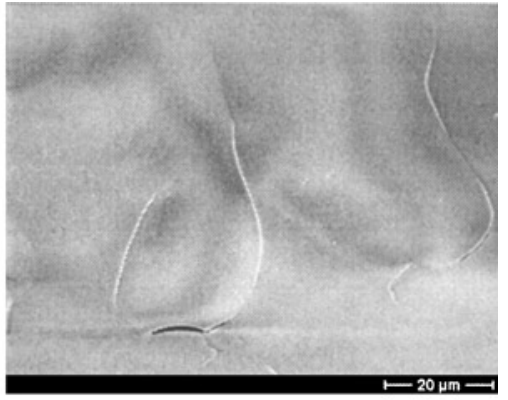

b)

FIGURE 4 SEM images of transferred layers of a) H-implanted STO and b) Heimplanted LAO. 


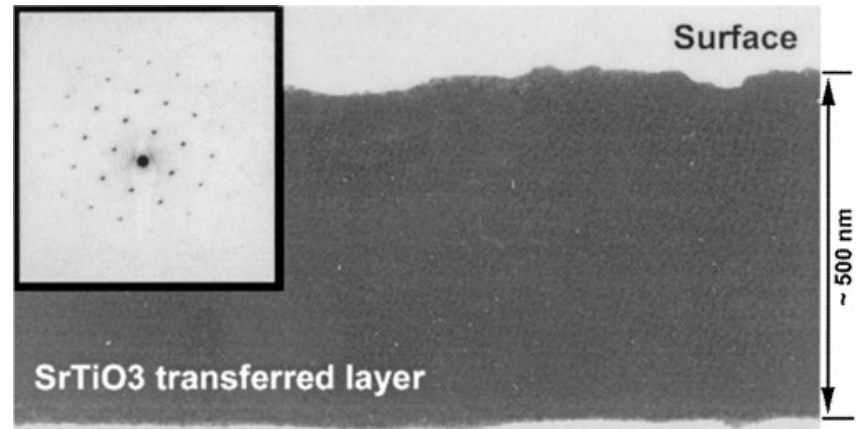

FIGURE 5 Cross-section TEM of a transferred STO layer. Inset: diffraction pattern of transferred layer.

almost impossible to bond such small samples because even single particles and edge defects coming from cutting and polishing procedure can destroy bonding conditions. Therefore whole wafers, that can be bonded more easily as Fig. 6 shows, should be implanted for wafer scale layer transfer. Additional problems with LAO bonding are expected because this crystal has a high micro-roughness of about $3 \mathrm{~nm}$ due to its twin structures. In this case direct wafer bonding can be obtained only after further improvement of the surface by fine polishing of substrates or surface activation [8].

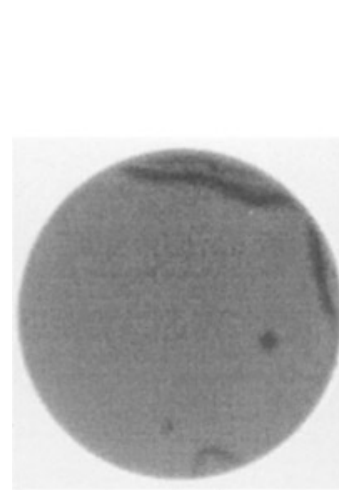

a)

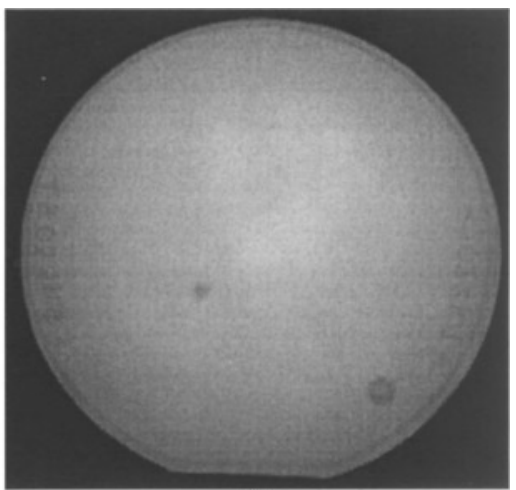

b)

FIGURE 6 IR images of direct bonded a) $30 \mathrm{~mm}$ diameter STO/STO wafers and b) $100 \mathrm{~mm}$ diameter inches $\mathrm{LNO} / \mathrm{LNO}$ wafers. 


\section{CONCLUSIONS}

A layer splitting approach combining helium and/or hydrogen implantation and wafer bonding was applied for the transfer of thin oxide layers onto different substrates. Blistering and exfoliation of oxides was shown. The specific implantation conditions for achieving blistering/splitting after a post-implantation annealing were successfully determined for each investigated oxide. Under certain implantation conditions large area exfoliation instead of blistering occurs after annealing of as-implanted oxides. Large area transfer (as large as $100 \mathrm{~mm}$ diameter for $\mathrm{LiNbO}_{3}$ ) should be possible after whole wafer implantation and thermal annealing of direct bonded wafers.

\section{ACKNOWLEDGMENTS}

The authors would like to thank S. Hopfe and B. Lausch for TEM sample preparation. The present work was funded by a Marie Curie Host Development Fellowship of the European Community program "Improving Human Research Potential and the Socio-economic Knowledge Base" under project HPMD-CT-2000-00015.

\section{REFERENCES}

[1] L.-J. Huang, Q.-Y. Tong, and U. Gösele, Electrochem. \& Solid-State Lett. 2, 238 (1999).

[2] M. Bruel, B. Aspar, B. Charlet, C. Maleville, T. Poumeyrol, A. Soubie, A. J. AubertonHerve, J. M. Lamure, T. Barge, F. Metral, and S. Trucchi, IEEE International SOI Proceedings 178 (1995).

[3] Q. Y. Tong and U. Gösele, "Semiconductor wafer bonding: Science and Technology," John Wiley \& Sons, New York, (1999).

[4] Q.-Y. Tong and U. Gösele, Adv. Mat. 11, 1404 (1999).

[5] M. Alexe, P. Kopperschmidt, U. Gösele, Q.-Y. Tong, and L.-J. Huang, Mat. Res. Soc. Proc. 574, 285 (1999).

[6] I. Radu, I. Szafraniak, R. Scholz, M. Alexe, and U. Gösele, Mat. Res. Soc. Symp. Proc. 748, U11.8.1 (2003).

[7] J. F. Ziegler, J. P. Biersack, and U. Littmark, "Stopping and range of ions in solids," Pergamon Press, (1985).

[8] C. B. Eom, L. Huang, R. A. Rao, Q. Y. Tong, and U. Gösele, IEEE Trans. Appl. Superconduct. 7, 1244 (1997). 